\title{
Altered homeostatic regulation of innate and adaptive immunity in lower gastrointestinal tract GVHD pathogenesis
}

\author{
James L.M. Ferrara, ${ }^{1}$ Christopher M. Smith, ${ }^{1}$ Julia Sheets, ${ }^{2}$ Pavan Reddy, ${ }^{3}$ and Jonathan S. Serody ${ }^{4}$ \\ 'Departments of Medicine, Pediatrics, and Academic Informatics and Technology, Icahn School of Medicine at Mount Sinai and Tisch Cancer Institute, New York, New York, USA. ${ }^{2}$ University of North Carolina \\ Hospital, Chapel Hill, North Carolina, USA. ${ }^{3}$ Department of Medicine and University of Michigan Comprehensive Cancer Center, University of Michigan, Ann Arbor, Michigan, USA. ${ }^{4}$ Department of Medicine \\ and UNC Lineberger Comprehensive Cancer Center, University of North Carolina, Chapel Hill, North Carolina, USA.
}

\begin{abstract}
Lower gastrointestinal (GI) tract graft-versus-host disease (GVHD) is the predominant cause of morbidity and mortality from CVHD after allogeneic stem cell transplantation. Recent data indicate that lower GI tract CVHD is a complicated process mediated by donor/host antigenic disparities. This process is exacerbated by significant changes to the microbiome, and innate and adaptive immune responses that are critical to the induction of disease, persistence of inflammation, and a lack of response to therapy. Here, we discuss new insights into the biology of lower GI tract CVHD and focus on intrinsic pathways and regulatory mechanisms crucial to normal intestinal function. We then describe multiple instances in which these homeostatic mechanisms are altered by donor T cells or conditioning therapy, resulting in exacerbation of CVHD. We also discuss data suggesting that some of these mechanisms produce biomarkers that could be informative as to the severity of CVHD and its response to therapy. Finally, novel therapies that might restore homeostasis in the GI tract during GVHD are highlighted.
\end{abstract}

\section{Lower gastrointestinal tract graft-versus-host} disease: where we were

Acute graft-versus-host disease (aGVHD) was noted as a complication of allogeneic bone marrow (BM) transplantation in animal models more than six decades ago $(1,2)$. The initial descriptions of aGVHD differentiated it from the complications of BM aplasia and focused on the severe consequences of GVHD for lower gastrointestinal (GI) tract function, as manifested by weight loss and profound diarrhea. Subsequent studies clearly identified donor $\mathrm{T}$ cells as the critical cells required for the induction of aGVHD (3-5). aGVHD was shown to predominantly involve the skin, liver, and lower GI tract and, later, the upper GI tract (6). In the absence of approaches to prevent aGVHD, this complication occurs in close to $100 \%$ of recipients of allogeneic BM/stem cell transplants (allogeneic hematopoietic cell transplantation, alloHCT), greatly limiting the survival of the first cohort of patients who underwent allo-HCT.

\section{Lower GI tract GVHD: clinical findings}

Despite the use of prophylaxis to prevent aGVHD, without rigorous T cell depletion this complication occurs in 30\%-70\% of patients undergoing allo-HCT (7-9). Standard treatment of aGVHD is the administration of systemic corticosteroids and additional immunosuppressive agents, which, as primary therapy, do not

Conflict of interest: J.L.M. Ferrara has intellectual property protection for the use of protein biomarkers to predict GVHD severity and outcomes for patients after allogeneic stem cell transplantation. J.S. Serody received consulting income from GeneCentric and grant support from Merck Inc.

Reference information: J Clin Invest. 2017;127(7):2441-2451.

https://doi.org/10.1172/JCI90592. substantially improve patient outcomes (10). Thirty to seventyfive percent of patients who develop aGVHD will have a complete response to corticosteroid therapy (11).

The outcome for patients with severe aGVHD (grades III-IV) of the lower GI tract is poor, with $25 \%$ overall survival (12). Four risk factors (corticosteroid resistance, age under 18 years at time of transplant, GI tract bleeding, and total bilirubin greater than $3 \mathrm{mg} / \mathrm{dl}$ ) were found on multivariate analysis to be statistically associated with poor survival; no patients with all 4 factors survived, highlighting the critical need to improve survival for these patients. This Review will focus on recent findings regarding the homeostatic mechanisms of the lower GI tract that relate to the pathophysiology of aGVHD involving the distal small intestine and colon.

\section{Immune homeostasis in the GI tract}

The immune balance of the human small intestine and colon is complex. There are over 100 trillion bacteria that are critical to the function of the GI tract, and individuals are exposed to a huge number of food-borne antigens on a daily basis. Thus, there must exist dynamic and robust mechanisms that mediate immune responses to pathogenic organisms but that prevent immune responses to normal flora and dietary antigens.

Antigen-presenting cells in the GI tract. Specialized hematopoietic antigen-presenting cells (APCs) in the GI tract include multiple subpopulations of dendritic cells (DCs) and macrophages (Figure 1). DCs in the lamina propria (LP) and Peyer's patch sample luminal antigens and migrate to regional lymph nodes (LNs) to activate immune responses $(13,14)$. Macrophages are sessile and are the most abundant innate immune cells in the intestine; they maintain homeostasis by phagocytosing microorganisms and apoptotic 


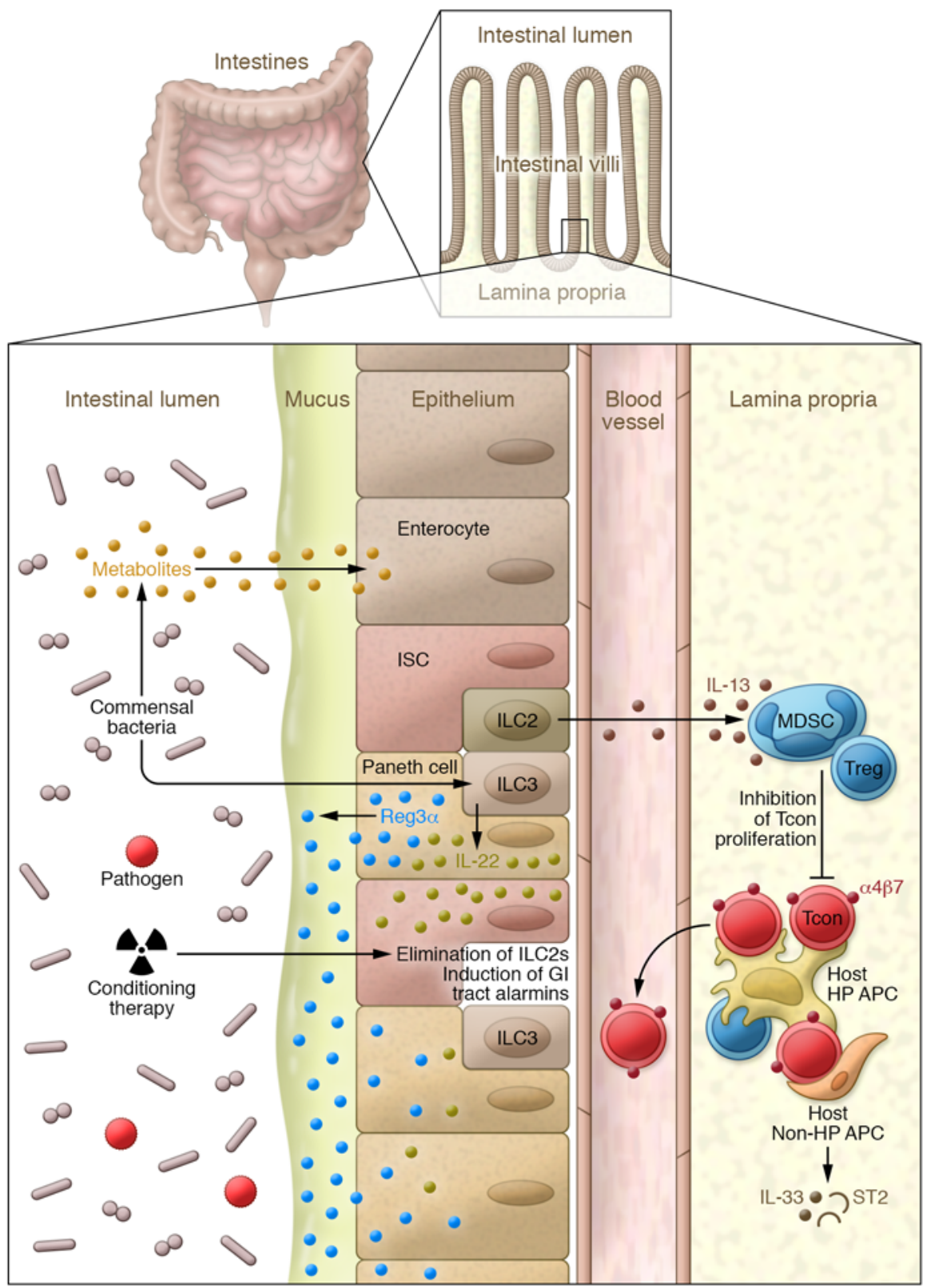

Figure 1. Early gastrointestinal GVHD pathophysiology. At steady state, intestinal stem cells (ISCs) reside next to Paneth cells at the base of intestinal crypts. Homeostasis is maintained, in part, by large numbers of commensal bacteria that stimulate IL-22 production by ILC3s. Commensal bacteria also produce metabolites such as butyrate, which promote the health of Tregs, as well as enterocytes and ILC2s, which maintain antiinflammatory myeloid-derived suppressor cells (MDSCs) and enhance GI barrier function. During allo-HCT, ILC2s are eliminated by hematopoietic cell transplant (HCT) conditioning, resulting in diminished antiinflammatory properties in the GI tract. However, ILC3s, which secrete IL-22 that protects ISCs and induces regenerating family member $3 \alpha$ (REG3) in Paneth cells, resist host conditioning. REC3 is concentrated in the mucus that shields the sterile surfaces of enterocytes from potential pathogens present in the intestinal microbiome. After allo-HCT, donor conventional T cells (Tcons) recognize histocompatibility antigens on both hematopoietic (HP) and non-HP APCs. Activated Tcons proliferate and trigger release of alarmins, such as IL-33 and its soluble receptor ST2, from non-HP APCs, such as stromal cells and endothelium; these activated Tcons also express the integrin receptor $\alpha_{4} \beta_{7}$, which directs their migration back to intestinal tissue after entering the villus capillaries. the IL-1 $\beta$ receptor antagonist anakinra (16). In response to commensal antigens, resident macrophages produce IL-1 $\beta$, which is critical to the maintenance of Th17 cells in the small intestine (17).

Intestinal DCs sample ingested material and present foreign antigens to naive $\mathrm{T}$ cells in the context of MHC molecules (18-20). Intestinal DCs are divided into 4 subsets based on their expression of CD103 and CD11b. CD $103^{+} \mathrm{CD} 11 \mathrm{~b}^{+}$DCs are prominent in the small intestine and migrate to draining mesenteric LNs, where they present luminal antigens to $\mathrm{T}$ cells (21). The $\mathrm{CD} 103^{+}$DC subset maintains tolerance to antigens at steady state, yet the same $\mathrm{CD}_{103}{ }^{+} \mathrm{DCs}$ convert to potent $\mathrm{T}$ cell activators during inflammation (22).

Adaptive immune cells in the GI tract. Lymphocytes in the intestinal tract are critical in balancing inflammation and tolerance to antigens (Figure 1). There is a unique interplay between the generation of lymphoid tissue, presence of lymphoid cells, and GI tract microbiota. IL-17A-producing $\mathrm{CD} 4^{+} \mathrm{T}$ cells (Th17), which are critical to the response to bacterial pathogens, exist in a dynamic equilibrium with inducible FoxP3 ${ }^{+}$Tregs in the lower GI tract; this equilibrium is regulated in part by specific microbial species $(23,24)$. In germ-free mice, few Tregs are found in the colon, although they can be induced by certain bacterial species. Tregs are normally present in the small intestine in germ-free mice and are maintained by dietary antigens (23). Both thymic-derived Tregs (tTregs) and inducible Tregs (iTregs) are generated from $\mathrm{CD}^{+} \mathrm{T}$ cells in the presence of specific stimuli such as TGF- $\beta$ and play a critical role in preventing immune responses to commensal bacteria and luminal dietary antigens. The LP houses a significant number of IgAproducing plasma cells throughout the entire intestine. Secretory IgA is dependent on the presence of the microbiota, and polymeric Ig receptor expression in the large intestine is dictated by the microbiota $(25,26)$.

After activation by APCs in the mesenteric LN, Peyer's patch, and cryptopatch, T cells express homing receptors such as the $\alpha_{4} \beta_{7}$ integrin that mediate their migration back to the GI tract (Figure 1 and ref. 27). The $\alpha_{4} \beta_{7}$ integrin binds to the mucosal vasenterocytes. Macrophages and DCs produce IL-10, which blocks proinflammatory responses and promotes survival and function of Tregs in the mucosa (15). Both humans and mice that lack the IL-10 receptor (IL-10R) develop spontaneous colitis that is responsive to cular addressin (MAdCAM-1) expressed by venules of the LP and high endothelial venules of the GI tract, and loss of the $\beta_{7}$ integrin leads to a significant decrease in LP T cells and antibody-secreting plasma cells. The chemokine receptor CCR9 is expressed by T cells 
that migrate to the small intestine in response to CCL25 generated by small bowel endothelial cells and stromal cells in the LP and intestinal crypts $(28,29)$.

Innate lymphoid cells. Mature $\mathrm{T}$ and $\mathrm{B}$ lymphocytes require the rearrangement of germline-encoded receptors to become specific for individual antigens (30). Research in the past decade has discovered a group of innate lymphoid cells (ILCs) that lack antigenspecific receptors and are present in mucosal sites such as the lung and GI tract $(31,32)$. Three different populations of ILCs with transcriptional networks similar to those of adaptive immune cells have been identified: ILC1s generate IFN- $\gamma$ in response to predominantly intracellular viral pathogens; ILC2s generate IL-4, IL-5, and IL-13, similarly to Th2 cells in response to nematodes; and ILC3s generate IL-17A and/or IL-22, similarly to Th17 and/or Th22 cells in response to pathogenic bacteria (33). ILC2s require the expression of the transcription factors GATA3 and ROR $\alpha$, while ILC3s require the expression of the aryl hydrocarbon receptor (AHR) and the RAR-related orphan receptor- $\gamma(\mathrm{ROR} \gamma \mathrm{t})$ transcription factors. Both ILC2s and ILC3s are found in the LP of the small bowel and colon, where they support epithelial cell barrier function, maintain both intestinal stem cells (ISCs) and Paneth cells, and promote antiinflammatory immune responses (Figure 1 and ref. 33).

\section{GVHD and innate immunity}

Alarmins. The homeostatic and regulatory mechanisms that limit GI tract inflammation to commensal flora or food-borne antigens are often targets during GVHD. Preparative chemo-radiation regimens for allo-HCT damage both host epithelium and hematopoietic cells (34). GI tract damage in patients undergoing allo-HCT is exacerbated via the release of inflammatory mediators from conditioning therapy. The GI damage caused by the conditioning regimens releases alarmins, including danger-associated molecular patterns (DAMPs), microbe-associated molecular patterns (MAMPs), and inflammatory cytokines (34-36). MAMPs interact with specific pattern recognition receptors (PRRs) (37-40); the stimulation of these receptors results in initiation and/or amplification of immune responses, triggers inflammation, and leads to tissue destruction and, occasionally, repair (41). Alarmins are the bestcharacterized DAMPs and include HSPs, high-mobility group box 1 (HMGB1), purine metabolites, uric acid (UA) crystals, histones, mitochondria, components of extracellular matrix heparan sulfate proteoglycans, syndecans, fibronectin, and inflammatory cytokines including IL-33 (refs. 38-40, 42-48, and Figure 1). Herein, we will focus on DAMP alarmins and their role in GI GVHD.

ATP is released from damaged cells and binds to the $\mathrm{P} 2 \mathrm{X}$ family of purinergic receptors, including P2X7 and P2Y2 (49-51). ATP engagement of $\mathrm{P} 2 \mathrm{X} 7$ on host hematopoietic APCs enhanced their activation, amplified stimulation of the alloreactive donor $\mathrm{CD} 4^{+}$ $\mathrm{T}$ cells, and enhanced Th1 responses (50), whereas interruption of this pathway decreased GI tract GVHD (50). Systemic administration of broad-spectrum P2X7 antagonists attenuated GVHD $(50,52)$. Likewise, GVHD was mitigated by the absence of another ATP purinergic receptor, P2Y2, on the host hematopoieticderived APCs (51). Increased extracellular ATP is regulated by ectonucleotidases such as CD73 (ecto-5-nucleotidase), which converts AMP to adenosine (53). Treatment of recipient mice with adenosine $A_{2 A}$ receptor agonists decreased GVHD, whereas the absence of CD73 on either donor T cells or host APCs exacerbated GVHD (54-56).

UA, a purine metabolite released from damaged cells, is an endogenous DAMP that stimulates DCs and activates $\mathrm{CD}^{+} \mathrm{T}$ cell cytotoxic functions $(45,57)$. Recent data show that UA contributes to GVHD severity by stimulating the NLRP3 inflammasome (57, 58). HMGB1 is a ubiquitous DNA-binding nuclear protein found in all eukaryotic cells that binds to nucleosomes and regulates gene transcription (46). It is released from damaged tissues and binds to PRRs such as TLR2, TLR4, and the receptor for advanced glycation end products (RAGE) (46, 59-62). Increased HMGB1 is observed in recipient mice after experimental allo-HCT (60), and treatment of hosts with indole-derived antioxidant mitigates the release of ROSdependent HMGB1 and reduces severity of GI tract GVHD (63). Consistent with murine data, an increase in serum levels of HMGB1 has been observed in patients with aGVHD (64), but these levels have not yet been correlated directly with the severity of GI tract GVHD.

Alarmins can both induce and suppress immune responses in the GI tract. Receptors with immunoreceptor tyrosine-based inhibitory motifs (ITIMs) or ITIM-like regions in their intracellular domains regulate DAMP-mediated innate inflammatory responses (65-68) and belong to the family of sialic acid-binding immunoglobulinlike lectins (Siglecs) (68). Siglec-G expression in host APCs plays an important role in protecting against DAMP-mediated GVHD due to tissue damage following conditioning $(69,70)$. Siglec-G interacts with its ligand CD24, a glycosylphosphatidylinositol-anchored glycoprotein expressed by T cells. Interestingly, CD24 negatively regulates DAMPs such as HMGB1 through a direct interaction of a trimolecular complex composed of Siglec-G, CD24, and HMGB1 (70). The interaction of Siglec-G with CD24 has been shown to limit the severity of GVHD in animal models (46). Furthermore, enhancing Siglec-G-CD24 activity using a novel CD24 fusion protein $(\mathrm{CD} 24 \mathrm{Fc})$ mitigated GVHD in multiple experimental BM transplant (BMT) models (70).

$\alpha_{1}$-Antitrypsin. $\alpha_{1}$-Antitrypsin (AAT), a serine protease inhibitor predominantly generated in the liver, possesses antiinflammatory properties that enhance the generation of IL-10 and TGF- $\beta$ and reduce the generation of IL- 6 by APCs (71). An initial role for AAT in the biology of GVHD came from studies indicating that it decreased IL-32 production in mixed lymphocyte responses (72). AAT treatment of recipient mice in a minor-mismatched GVHD model diminished GI tract inflammation, decreased generation of proinflammatory cytokines and effector cells, increased generation of Tregs and host APC IL-10 production, and improved survival (73).

\section{Inflammasomes and GI tract GVHD}

Inflammasomes such as NLRP2, NLRP3, and NLRP6 are large cytosolic complexes that sense DAMPs and activate caspase-1 and -11, resulting in the production of the proinflammatory cytokines IL-1 $\beta$ and IL-18 (74). NLRP3 activation enhanced GVHD (57, 58), and donor NLRP3 polymorphisms have been associated with outcomes after allo-HCT (75). Two genetic variants in donor NLRP3 were associated with an increased risk of disease relapse (75). An increased risk for grades III-IV aGVHD was found in recipients with the NLRP2 CC genotype compared with CA/AA (75). Additionally, 2 genetic variants in NLRP2 in both donor and patient were associated with inferior nonrelapse mortality and survival (75). NLRP6 is expressed 


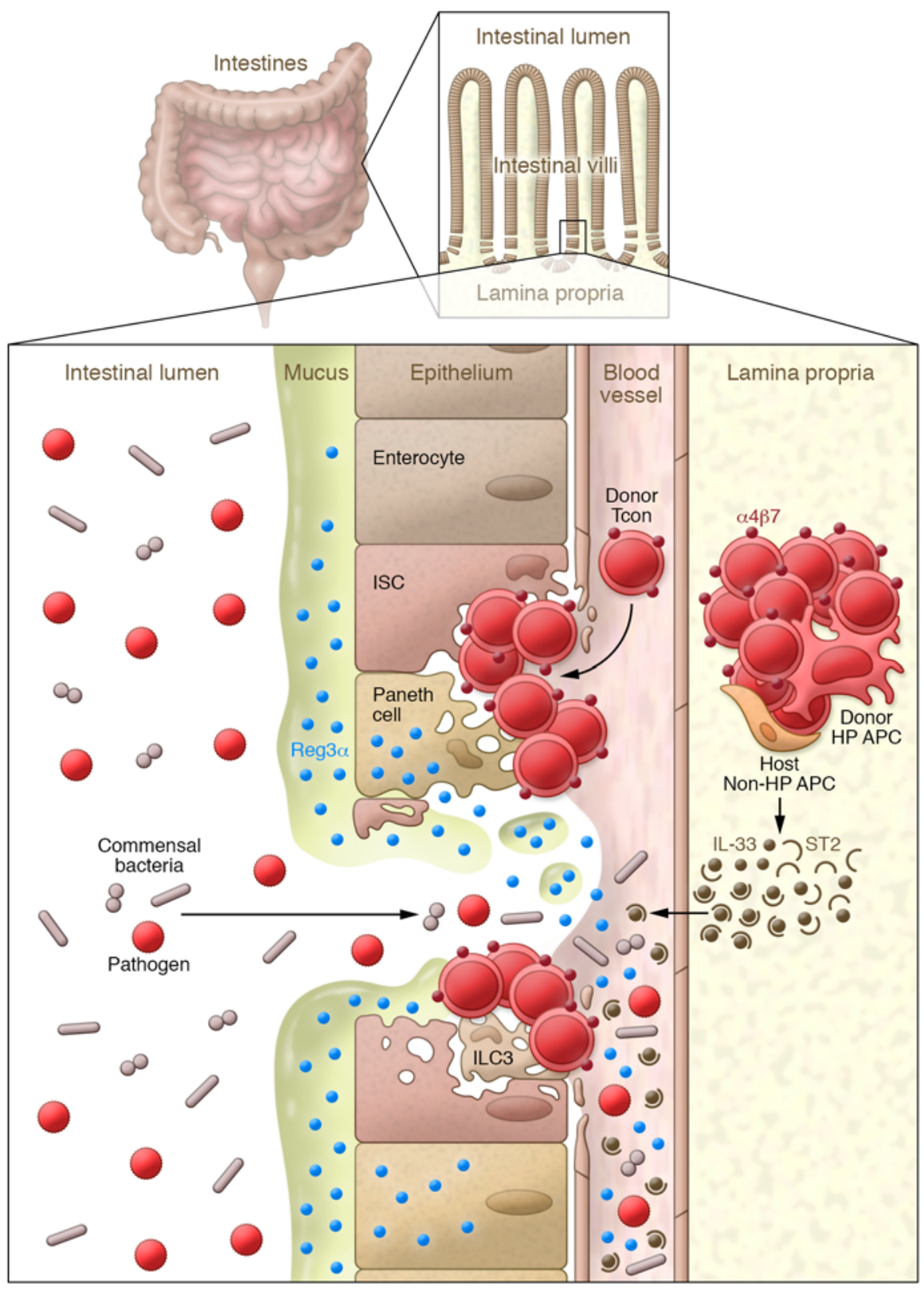

Figure 2. Late gastrointestinal GVHD pathophysiology. Activated Tcons have migrated back to the intestinal crypts and have eliminated host APCs and Tregs. Donor HP APCs that have differentiated from donor HP stem cells migrate to the colon, where they continue to present host antigens together with non-HP APCs, driving them to amplify the inflammatory cascade and to secrete large amounts of IL-33 that binds ST2 before entering the villus capillaries. Tcons have eliminated ILC3s, Paneth cells, and ISCs. Commensal bacteria (and their metabolites) no longer predominate, permitting overgrowth of potential pathogens. REC3 stored in the mucus and in Paneth cells enters the bloodstream as the epithelial barrier is lost. a critical role for host BM DCs or plasmacytoid DCs (pDCs) when transferred into MHC-deficient recipients (80-82). By contrast, studies with host B cell transfer did not induce GVHD (80). Loss-of-function studies demonstrated that recipient $\mathrm{CD} 11 \mathrm{c}^{+}$ DCs are not required to initiate $\mathrm{CD} 4^{+} \mathrm{T}$ cellmediated GI GVHD $(83,84)$. Furthermore, neither recipient macrophages, pDCs, B cells, basophils, nor Langerhans cells were required to initiate GVHD when other APCs were competent, suggesting considerable redundancy among professional hematopoietic APCs (83-85). Importantly, recent studies show that recipient nonhematopoietic APCs can also initiate GVHD, as schematized in Figure 2 and ref. 86. Additionally, donor APCs can amplify GI GVHD, particularly donor $\mathrm{CD}_{103}{ }^{+} \mathrm{DCs}$ that migrate from the mesenteric LNs to the colon via CCR7. Activation of donor $\mathrm{CD}_{103}{ }^{+} \mathrm{DCs}$ in response to MyD88/TIR domain-containing adaptorinducing interferon- $\beta$ (TRIF) or RAGE signals (22) was critical to their function and the generation of IL-12p40.

Neutrophils are professional phagocytic cells that possess a vast array of antimicrobial functions allowing for rapid clearance of bacterial pathogens (87). A role of neutrophils in the pathogenesis of aGVHD has been demonstrated, as total-body irradiation led to an increase in the migration of neutrophils to the GI tract dependent on the presence of microbial flora in the ileum (88). Transfer of TLR-expressing neutrophils enhanced GVHD mortality compared with the decreased mortality found after the transfer of TLR-deficient neutrophils. The transfer of BM cells lacking SMAD3, a critical signaling component of the TGF- $\beta$ axis, greatly increased GVHD lethality, which correlated with enhanced Th1 polarization of donor $\mathrm{T}$ cells and neutrophil recruitment to the GI tract, mesenteric LNs, and spleen (89). Depleting myeloid cells using anti-Gr-1 $m A b$ therapy greatly improved the outcome of mice receiving SMAD-deficient BM (89). in intestinal epithelial cells (IECs) and regulates epithelial homeostasis and the gut microbiome $(69,76)$. NLRP6 deficiency improved GVHD, but exacerbated experimental inflammatory bowel disease $(76,77)$. Further, BM chimera experiments have suggested a role for nonhematopoietic expression of NLPR6 in GI tract GVHD (48).

\section{APCs and GI tract GVHD}

Host APCs are key to the induction of $\operatorname{GVHD}(78,79)$. Earlier studies that primarily used adoptive transfer approaches demonstrated

\section{Microbiome and GI GVHD}

Forty years ago, van Bekkum and Knaan reported that germ-free mice had minimal GVHD (90). This observation led to widespread use of antibiotics to "decontaminate" the GI tract before and during allo-HCT. Initial studies of antibiotics to decontaminate the GI tract suggested promising results $(91,92)$, but other studies demonstrated no benefit with broad-spectrum antibiotics. By contrast, a recent analysis demonstrated that broad-spectrum antibiotic use, specifically agents with activity against anaerobes such as imipe- 
nem/cilastatin and piperacillin/tazobactam, was associated with increased GVHD-related mortality. In contrast, cefepime and aztreonam, which have very limited anaerobic activity, were not associated with GVHD-related mortality (93). Interestingly, prophylaxis with rifaximin, a nonabsorbed broad-spectrum oral antibiotic, was associated with a decrease in Enterococcus species, higher levels of urinary 3-indoxyl sulfate, which is associated with the presence of Clostridiales, and improved survival compared with ciprofloxacin and the antianaerobic antibiotic metronidazole (94).

Experimental models have shown a persistent loss of GI microbial diversity in animals with $\operatorname{GVHD}(95,96)$, and the magnitude of the loss correlated with treatment-related mortality after allo-HCT (97). Loss of commensals such as Blautia and Lactobacillus is associated with the overgrowth of pathogens such as Proteobacteria and Enterococcus, which correlates with GI GVHD (93, 97-99). It is not yet clear whether antibiotic dysbiosis is a primary or secondary phenomenon in GVHD. In support of the former, the microbiota seems to be influenced by the host's genotype; in support of the latter, infections, antibiotics, drugs, and diet can all induce dysbiosis (100). The fundamental question of whether dysbiosis alone is sufficient to cause GVHD remains to be answered.

Microbial metabolites and GI GVHD. The microbiota metabolizes material directly ingested by the host, producing its own metabolites. The intestinal metabolome therefore consists of products from discrete host metabolism, microbial metabolism, and mammalian/microbial cometabolism (101). The impact of microbiotaderived metabolites is increasingly appreciated in intestinal homeostasis (101). Short-chain fatty acids (SCFAs) are the most thoroughly studied microbial metabolites and are absorbed by the intestinal epithelium following the fermentation of complex polysaccharides in the gut $(100,101)$. The SCFA butyrate is the major energy source for IECs $(100,101)$. In one study, the concentration of butyrate was significantly decreased in intestinal tissue after allo-HCT, although the concentrations of other SCFAs were not significantly changed in either serum or tissues (102). Reduced butyrate in CD326 ${ }^{+}$IECs after allo-HCT contributed to decreased histone acetylation, which was restored after local administration of exogenous butyrate, resulting in improved IEC junctional integrity, increased antiapoptotic proteins, decreased GVHD, and improved survival (102). Additionally, alteration of the indigenous microbiota with 17 rationally selected strains of high-butyrateproducing Clostridia species also decreased GI tract GVHD and increased survival after allo-HCT (102-104).

The expression of indoleamine dioxygenase (IDO) is increased in intestinal cells and APCs after allo-HCT $(105,106)$. High IDO expression depletes tryptophan, resulting in apoptosis of alloreactive donor $\mathrm{T}$ effectors and generation of iTregs $(107,108)$. Aside from these direct immune regulatory activities, IDO-generated tryptophan by-products may also suppress GVHD directly (89). Clinical studies showed that lower levels of urinary 3-indoxyl sulfate, an indole metabolite influenced by commensal bacteria, correlated with decreased patient survival after allo-HCT (109). A recent clinical study showed an association between GVHD, the need for parenteral nutrition, the loss of microbial diversity, and reduced levels of Blautia (98). In mouse models, antibiotic treatment worsened GVHD, increased gut damage, and was associated with increased Akkermansia, a mucus-devouring microbe
(93). These data support the hypothesis that GI microbial taxonomy impacts the severity of GVHD through effects on adaptive immune responses and/or target tissues.

\section{Inflammatory cytokines}

Inflammatory cytokines synergize with cytotoxic T cells to amplify local tissue injury and promote inflammation, which ultimately leads to target tissue destruction in the BMT recipient (110). Th1 cytokines (IFN- $\gamma$, IL-2), TNF, and IL- 6 have often been implicated in the cytokine storm that occurs early after BMT and have been shown to be critical for the pathophysiology of aGVHD (111-113). In addition to IL-2, several other common $\gamma$ chain cytokines (IL-21, IL-7, and IL-15) play a critical and potentially nonredundant role in GVHD pathogenesis (114). Tc1/Th1 maturation is recognized as the dominant pattern in aGVHD $(115,116)$. Increased quantities of the Th1 cytokines TNF and IFN- $\gamma$ are associated with early onset of aGVHD and more severe disease in both preclinical models and clinical BMT. Th2 and Th17 subsets may also mediate GVHD pathology, and the balance between subsets determines aGVHD severity in various target organs (117-120). Th17 differentiation is initiated by IL-6 (121) with ROR $\gamma \mathrm{t}$ as the defining transcription factor, whereas maintenance and amplification of these cells rely on IL-23 and IL-21, respectively. The use of RORC-deficient donor T cells attenuates aGVHD severity and lethality (122), and the elimination of hyperinflammatory Tc17 early after BMT reduces GI GVHD and improves survival without diminishing graft-versusleukemia effects (123).

Recent data suggest that IL- 6 is a critical cytokine that increases GVHD severity. It has direct cytopathic effects on the GI tract following allogeneic BMT and likely inhibits the suppressive function of Tregs (113). IL-6 and the Th17/Tc17 pathway play a critical role in the microbial ecology after allo-BMT. Mice lacking IL-17A, IL-17F, or their receptors developed significant GI tract GVHD, which correlated with microbial dysbiosis (124). IL-23, generated by donor APCs, has been shown to play a critical role in the induction of GVHD in the lower GI tract (125). Recently, a population of $\mathrm{CD}^{+} \mathrm{T}$ cells that coexpresses the IL-23 receptor, CD11c, and innate cell TLR and NLR proteins was shown to be critical to the induction of GI GVHD by IL-23. IL-10 generated by non-Tregs was critical in controlling inflammation by these cells (126).

IL-33, a member of the IL-1 family, has generated particular interest because soluble ST2, a decoy receptor for IL-33, is a blood biomarker for steroid-resistant GVHD (127). During GVHD, IL-33 levels increase dramatically in the GI tract, especially IL-33 produced by nonhematopoietic cells such as endothelial cells and stroma (Figure 2 and ref. 128). Mice that are deficient in IL-33 experience less severe GVHD, and donor T cells that lack the membrane-bound IL-33 receptor mST2 generate less IFN- $\gamma$ and TNF compared with their WT counterparts, leading to reduced GVHD. Blockage of IL-33/ST2 interactions can also protect mice from lethal GVHD (128). As noted above, IL-33 can be classified as an alarmin, and the damaged tissue that releases IL-33 also secretes soluble ST2 (129). However, IL-33 has pleiotropic effects, and administration of IL-33 prior to BMT can drive proliferation of Tregs and ILC2s (our unpublished data) that prevent experimental GVHD (130). Thus, the effect of therapeutic strategies to manipulate the IL-33/ST2 axis in clinical HCT may not be straightforward. 


\section{Resident GI tract cells}

Paneth cells. Paneth cells, which are found adjacent to ISCs in the intestine, secrete multiple antimicrobial peptides including $\alpha$-defensins as well as lysozyme and phospholipase $A_{2}$, all of which help to generate the chemical/physical barrier of the GI mucosa. The loss of Paneth cells and $\alpha$-defensins was a major manifestation of GI GVHD in an experimental model, where the resulting loss of microbial diversity allowed the expansion of pathogenic $E$. coli (131). The antimicrobial peptide regenerating family member $3 \alpha$ (REG3) is produced by Paneth cells and can modulate the microbiome by inhibiting the growth of pathogenic bacteria while sparing nonpathogenic commensal bacteria. Because of its large size, REG3 concentrates in the mucus, where it prevents enterococci from adhering to enterocytes (Figure 2 and ref. 132). Loss of commensal bacteria leads to diminished intestinal microbial diversity that is observed in both experimental and clinical GVHD (95).

The principal inducer of REG3 in both Paneth cells and other enterocytes is IL-22, which is produced by ILC3s (Figure 2). Administration of IL-22 induces REG3 and protects ISCs, preventing a breach in the GI epithelial barrier and reducing GI GVHD (133). Paneth cell loss probably reflects the loss of ISCs, which are not readily visible by standard histologic techniques (134).

ILC3s. ILC3s constitute a very heterogeneous population of immune cells with inherent plasticity. There are multiple different lineages of ILC3s, and one approach to classifying these cells is based on expression of the chemokine receptor CCR6. CCR6 $6^{+}$ ILC3s can be subdivided into those that express CD4, while CCR6 ILC3s are characterized by the expression of natural cytotoxicity receptors (NCRs; NKp46 in mice and NKp44 in humans) (31).

ILC3s play a critical role in modulating inflammation during GVHD (Figure 2 and ref. 133). ILC3s persist in the LP after conditioning therapy and BMT, and these cells generate IL-22 in response to IL-23. The ILCs that generate IL-22 are CCR6 ${ }^{+} \mathrm{NKp} 46$ IL-7 $\mathrm{R}^{+}$, consistent with the subset of lymphoid tissue inducerlike (LTi-like) cells that generate IL-22 (133). Interestingly, after irradiation and allo-BMT, murine LTi-like ILC3s in the LP were predominantly derived from the host up to 3 months after BMT. During aGVHD, ILC3s are lost, as are leucine-rich repeatcontaining GPCR $-5^{+}\left(\mathrm{LGR}^{+}\right)$columnar base epithelial cells (an ISC phenotype). Recent work using intestinal organoid cultures has demonstrated that IL-22 acts on ISCs (135). Treatment of mice starting 1 week after allo-BMT with Fc-fusion recombinant human IL-22 (F-652) significantly improved survival in a minor-MHCmismatch transplant model (123). As noted above, when ILC3s were lost during GVHD, administration of IL-22 increased Paneth cell production of REG3 and protected mice from mortality (133). Thus, IL-22 both enhances ISC numbers and induces antimicrobial peptides such as REG3 in the GI tract.

A second approach to enhance the function of ISCs in the GI tract was demonstrated using the potent WNT signaling activator R-spondin-1. WNT activation is critical to the persistence of ISCs (136). Administration of R-spondin-1 to mice undergoing allo-BMT significantly decreased the production of TNF and IFN- $\gamma$, reduced the expansion of proinflammatory donor $\mathrm{T}$ cells, and improved overall survival in comparison with control-treated animals (137).

ILC2s. In contrast to the persistence of host ILC3s after conditioning therapy, recent work demonstrated that ILC2s in the LP were markedly depleted by both irradiation and cytotoxic chemotherapy and did not recover significantly from donor BM cells (138). Interestingly, ILC2s in the lung were not depleted by either treatment. The administration of ex vivo-expanded ILC2s markedly diminished aGVHD in the lower GI tract with improvement in survival with infusion on day 0 (preventative) or day 7 (treatment) (138). Infusion of donor ILC2s significantly decreased the generation of proinflammatory donor $\mathrm{T}$ cells in the colon and small bowel, which was associated with enhanced numbers of donor myeloid-derived suppressor cells in the lower GI tract. The antiinflammatory effects of ILC2s were dependent on their generation of IL-13, while production of amphiregulin by donor ILC2s was required for maintenance of the epithelial barrier after transplant.

\section{Clinical studies}

ILCs in GVHD. There is increasing evidence of a potential role for ILCs in patients after allo-HCT. Circulating ILC2s are diminished after both chemotherapy and allo-HCT (139). Twelve weeks after transplant there was a significant decrease in ILC2s with a more modest but significant decrease in ILC1s and NCR ILC3s. By contrast, $\mathrm{NCR}^{+}$ILC3s were significantly increased. Patients with increased proportions of activated (CD69+) ILCs prior to transplant had a significantly reduced incidence of aGVHD and mucositis. Additionally, patients with an increased number of $\alpha_{4} \beta_{7}^{+}$ ILC2s and/or NCR ${ }^{-}$ILC3s prior to transplantation had a diminished incidence of aGVHD of the lower GI tract.

Another group of investigators evaluated the recovery of ILCs after allo-HCT (140). They found that ILC numbers decreased in older individuals and were greatest in cord blood products. Patients with severe combined immunodeficiency, which included JAK3 or IL-2R $\gamma$ mutations (ILCs are absent in patients with IL-2R $\gamma$ mutations), who received nonmyeloablative conditioning had almost no detectable ILC2s or ILC3s in the bloodstream after transplant. Similarly, a subset of these patients had a significant deficiency in $\mathrm{NCR}^{+}$ILCs in the skin and GI tract after transplant. This was not found in pediatric patients undergoing myeloablative conditioning for the treatment of leukemia, indicating an ability to reconstitute ILCs from pediatric donors but only after myeloablative conditioning. The authors demonstrated impaired recovery of donor-derived ILC2s and ILC3s in mice after nonmyeloablative compared with myeloablative conditioning and syngeneic BMT, confirming clinical data showing that ILC2s and ILC3s are poorly regenerated from donor BM, especially after nonmyeloablative conditioning therapy. These data suggest that the reconstitution of peripheral ILCs, especially ILC2s and NCR ${ }^{-}$ILC3s from adult donor BM and/or peripheral blood stem cells, or from pediatric donors after nonmyeloablative conditioning, may be suboptimal.

Biomarker evaluations. Soluble ST2 levels are elevated in the blood early after allo-HCT, and an algorithm using both ST2 and REG3 concentrations has been validated to predict lethal GVHD 7 days after transplant in a very large (1,287 patients) multicenter data set (141). REG3 emerged from an unbiased proteomic screen to identify plasma biomarkers specific for GI GVHD, and in a multicenter data set of more than 1,000 patients, blood levels of REG3 increased fourfold in patients with lower GI tract GVHD but not in patients with enteritis from other causes (142). 
Table 1. Clinical approaches to enhancing homeostatic mechanisms in the GI tract during GVHD

\begin{tabular}{|c|c|}
\hline Cell process/mechanism & Function \\
\hline P2X receptors $(50)$ & $\begin{array}{l}\text { Binding of ATP enhances APC activation and proinflammatory } \\
\text { donor T cells }\end{array}$ \\
\hline$\alpha_{1}$-Antitrypsin $(72,73)$ & $\begin{array}{l}\text { Modulates APCs to increase Tregs and decrease effector T cells; } \\
\text { reduces IL-32 generation }\end{array}$ \\
\hline$\beta_{7}$ Integrin (146-148) & Promotes trafficking of T cells to the colon and small bowel \\
\hline MAdCAM-1 (149) & Addressin that binds to $\alpha_{4} \beta_{7}$ integrins \\
\hline IL-6 $(111,113)$ & Decreased Treg numbers; increased proinflammatory donor T cells \\
\hline IL-23 $(125,150,151)$ & $\begin{array}{l}\text { Enhances proinflammatory cytokine production } \\
\text { by donor } \mathrm{T} \text { cells }\end{array}$ \\
\hline $\begin{array}{l}\text { IL-18 generation via } \\
\text { inflammasome induction (152) }\end{array}$ & Reduces Th1 generation; induces Th2 polarization \\
\hline $\begin{array}{l}\text { IL-1 } \beta \text { generation via } \\
\text { inflammasome induction (153-155) }\end{array}$ & Induces Th17 polarization; inhibits MDSCs and Tregs \\
\hline $\begin{array}{l}\text { Enhanced microbial diversity } \\
(95,98,156-158)\end{array}$ & $\begin{array}{l}\text { Promotes persistence of Tregs, decreases donor } \\
\text { proinflammatory T cells }\end{array}$ \\
\hline Short-chain fatty acids $(104,159)$ & Enhances numbers of Tregs \\
\hline Antimicrobial peptides & $\begin{array}{l}\text { Mediate antimicrobial activity; promote barrier repair; activate } \\
\text { immunosuppressive immune cells }\end{array}$ \\
\hline ISC maintenance $(133,135,137,160)$ & Promotes persistence of ISCs; enhances activity of Paneth cells \\
\hline Donor/third-party ILC2 cells (138) & Enhances numbers of MDSCs and GI tract barrier protection \\
\hline Donor/third-party MDSCs (161-163) & Reduces number/function of proinflammatory donor T cells \\
\hline Donor/third-party Tregs (164-167) & Enhances number of Tregs in the GI tract \\
\hline Donor/third-party MSCs $(168,169)$ & $\begin{array}{l}\text { Induces APC production of IL-10 and prostaglandin } \mathrm{E}_{2} \text { and } \\
\text { decreases proinflammatory T cells }\end{array}$ \\
\hline
\end{tabular}

P2R inhibitors

$\alpha_{1}$-Antitrypsin systemic delivery

$\beta_{7}$-Specific mAbs, including vedolizumab, etrolizumab, and AMG181

MAdCAM-1-specific mAb PF-00547659

IL-6 receptor-targeting mAb tocilizumab

Ustekinumab and briakinumab are specific for the p40 subunit of IL-23 and IL-12

IL-18 cytokine therapy

IL-1 receptor antagonist anakinra

Donor stool transplant; delivery of bacterial strains

that induce Tregs

Butyrate or propionate infusions

REG3 infusion

IL-22 fusion protein; R-spondin-1 administration

Ex vivo administration of ILC2 cells

Ex vivo administration of MDSCs

Ex vivo administration of donor/third-party Tregs

Ex vivo administration of third-party MSCS

MDSC, myeloid-derived suppressor cell; MSC, mesenchymal stem cell.

The degree of REG3 elevation also predicted clinical response to GVHD therapy and correlated with increased Paneth cell loss, suggesting that increased levels reflected damage in the GI tract (142). A further analysis of BMT patients demonstrated that the loss of Paneth cells in biopsies was positively correlated with the clinical severity of GI tract GVHD (143). The number of Paneth cells inversely correlated with eventual response to treatment for GVHD and with nonrelapse mortality, which was primarily from GI tract GVHD.

Therapeutic approaches. While many of the findings in this Review are quite early in development and have yet to be translated, there are novel therapies that have emerged from our enhanced understanding of GI tract biology (Table 1). Significant responses to AAT have been observed in small, single-center, phase I/II trials for the treatment of steroid-refractory GVHD (144). AAT is currently being evaluated in a multi-institutional clinical trial as therapy for steroid-refractory lower GI tract GVHD (NCT02956122, ClinicalTrials.gov). Numerous investigators are evaluating whether reconstitution of a diverse microbiome can reduce GI tract GVHD via either stool transplantation, the administration of specified types of bacteria, the administration of compounds that alter the microbiome (NCT02763033), or allo-HCT out of the hospital (NCT01725022). The role of IL-22 in the maintenance of ISCs and the generation of REG3 has led to a clinical trial (NCT02406651) using F-652 with steroids for the treatment of patients with new-onset grades II-IV aGVHD of the lower GI tract.
The critical role for IL- 6 in the biology of aGVHD was recently demonstrated in a phase I/II trial of 48 patients using the IL-6 receptor-targeted $\mathrm{mAb}$ tocilizumab $(8 \mathrm{mg} / \mathrm{kg}) 1$ day before allo-HCT from HLA-identical siblings along with standard calcineurin inhibition and methotrexate (145). The incidence of grades II-IV GVHD at day 100 was $12 \%$; the incidence of grades II-IV GI tract GVHD was $8 \%$. Overall survival was $84 \%$ at 24 months with $68 \%$ of patients experiencing relapse-free survival. A phase III trial currently in progress should definitively address the ability of tocilizumab to prevent aGVHD (www.cancertrialsaustralia.com/Clinical-Trials-Register. aspx; ACTRN12614000266662).

\section{Conclusions}

Control of inflammation in the GI tract is an extremely complex process requiring intricate interactions between innate and adaptive immune cells, APCs, epithelia, stroma, and the microbiome, and the consequent generation of alarmins, cytokines, effector cells, and other mediators of inflammation. The activation of donor T cells by host cells in the GI tract perturbs many of these processes, generating alarmins and cytokines that enhance the proinflammatory activity of innate immune cells and that inhibit local immunosuppressive pathways. Donor $\mathrm{T}$ cells mediate the loss of ILC3s, leading to diminished numbers of ISCs and decreased function of Paneth cells through decreased production of antibacterial peptides. Conditioning therapy leads to loss of ILC2s and diminished antiinflammatory properties in the GI tract with impaired barrier repair. Finally, all of these processes alter 
the microbiome, leading to changes in metabolites and the diminished function of immunosuppressive mechanisms and cells such as Tregs. Our increased understanding of this complex system has led to a new understanding of GI GVHD as a failure to reconstitute normal mucosal immunity that ultimately results in the loss of critical ISCs, crypt damage, and disruption of the GI tract epithelial barrier. This new focus on the interactions between the innate and the adaptive immune system has led to new and unexpected approaches to therapeutic strategies.

\section{Acknowledgments}

This work was supported by grant NCI R01 CA166794 (to JSS); grant NCI P01 CA039521 and the American Cancer Society (to JLMF); and grant NCI R01 CA203542 (to PR).

Address correspondence to: Jonathan S. Serody, University of North Carolina School of Medicine, 125 Marsico Hall, Chapel Hill, North Carolina 27599-7295, USA. Phone: 919.966.6975; Email: Jonathan_Serody@med.unc.edu.
1. Billingham RE. The biology of graft-versus-host reactions. Harvey Lect. 1966;62:21-78.

2. Gatti RA, Kersey JH, Yunis EJ, Good RA. Graftversus-host disease. Prog Clin Pathol. 1973;5:1-18.

3. McKenzie IF, Snell GD. Comparative immunogenicity and enhanceability of individual $\mathrm{H}-2 \mathrm{~K}$ and $\mathrm{H}-2 \mathrm{D}$ specificities of the murine histocompatibility-2 complex. J Exp Med. 1973;138(1):259-277.

4. Benacerraf B, Kapp JA, Pierce CW, Katz DH. Genetic control of immune responses in vitro. IV. Conditions for cooperative interactions between nonresponder parental B cells and primed (responder plus nonresponder) F1 T cells in the development of an antibody response under Ir gene control in vitro. JExpMed.1974;140(1):185-198.

5. Glucksberg H, et al. Clinical manifestations of graft-versus-host disease in human recipients of marrow from HL-A-matched sibling donors. Transplantation. 1974;18(4):295-304.

6. Weisdorf DJ, et al. Acute upper gastrointestinal graft-versus-host disease: clinical significance and response to immunosuppressive therapy. Blood.1990;76(3):624-629.

7. Przepiorka D, et al. Risk factors for acute graftversus-host disease after allogeneic blood stem cell transplantation. Blood. 1999;94(4):1465-1470.

8. Verneris MR, et al. HLA mismatch is associated with worse outcomes after unrelated donor reduced-intensity conditioning hematopoietic cell transplantation: an analysis from the Center for International Blood and Marrow Transplant Research. Biol Blood Marrow Transplant. 2015;21(10):1783-1789.

9. Pidala J, et al. Amino acid substitution at peptidebinding pockets of HLA class I molecules increases risk of severe acute GVHD and mortality. Blood. 2013;122(22):3651-3658.

10. Bolaños-Meade J, et al. Phase 3 clinical trial of steroids/mycophenolate mofetil vs steroids/ placebo as therapy for acute GVHD: BMT CTN 0802. Blood. 2014;124(22):3221-3227.

11. Westin JR, et al. Steroid-refractory acute GVHD: predictors and outcomes. Adv Hematol. 2011;2011:601953.

12. Castilla-Llorente C, et al. Prognostic factors and outcomes of severe gastrointestinal GVHD after allogeneic hematopoietic cell transplantation. Bone Marrow Transplant. 2014;49(7):966-971.

13. Brandtzaeg P. Homeostatic impact of indigenous microbiota and secretory immunity. Benef Microbes. 2010;1(3):211-227.

14. Persson EK, Scott CL, Mowat AM, Agace WW. Dendritic cell subsets in intestinal lamina propria. Eur J Immunol. 2013;43(12):3098-3107.

15. Hadis $\mathrm{U}$, et al. Intestinal tolerance requires gut homing and expansion of FoxP3+ regulatory $\mathrm{T}$ cells in the lamina propria. Immunity. 2011;34(2):237-246.

16. Shouval DS, et al. Interleukin $1 \beta$ mediates intestinal inflammation in mice and patients with interleukin 10 receptor deficiency. Gastroenterology. 2016;151(6):1100-1104.

17. Shaw MH, Kamada N, Kim YG, Núñez G. Microbiota-induced IL-1 $\beta$, but not IL-6, is critical for the development of steady-state TH17 cells in the intestine. JExp Med.2012;209(2):251-258.

18. Pabst O, Mowat AM. Oral tolerance to food protein. Mucosal Immunol. 2012;5(3):232-239.

19. Liu LM, MacPherson GG. Antigen acquisition by dendritic cells: intestinal dendritic cells acquire antigen administered orally and can prime naive T cells in vivo. J Exp Med. 1993;177(5):1299-1307.

20. Luda KM, et al. IRF8 transcription-factordependent classical dendritic cells are essential for intestinal T cell homeostasis. Immunity. 2016;44(4):860-874.

21. Flannigan KL, Geem D, Harusato A, Denning TL. Intestinal antigen-presenting cells: key regulators of immune homeostasis and inflammation. Am J Pathol. 2015;185(7):1809-1819.

22. Koyama M, et al. Donor colonic $\mathrm{CD} 103^{+}$dendritic cells determine the severity of acute graft-versushost disease. J Exp Med. 2015;212(8):1303-1321.

23. Kim KS, et al. Dietary antigens limit mucosal immunity by inducing regulatory $\mathrm{T}$ cells in the small intestine. Science. 2016;351(6275):858-863.

24. Ivanov II, et al. Induction of intestinal Th17 cells by segmented filamentous bacteria. Cell. 2009;139(3):485-498.

25. Lin M, Du L, Brandtzaeg P, Pan-Hammarström Q. IgA subclass switch recombination in human mucosal and systemic immune compartments. Mucosal Immunol. 2014;7(3):511-520.

26. Brandtzaeg P. Secretory IgA: designed for antimicrobial defense. Front Immunol. 2013;4:222.

27. Meenan J, Spaans J, Grool TA, Pals ST, Tytgat GN, van Deventer SJ. Altered expression of $\alpha 4 \beta 7$, a gut homing integrin, by circulating and mucosal T cells in colonic mucosal inflammation. Gut. 1997;40(2):241-246.

28. Papadakis KA, Targan SR. The role of chemokines and chemokine receptors in mucosal inflammation. Inflamm Bowel Dis. 2000;6(4):303-313.

29. Papadakis KA, et al. The role of thymusexpressed chemokine and its receptor CCR9 on lymphocytes in the regional specialization of the mucosal immune system. Jimmunol. 2000;165(9):5069-5076.

30. Litman GW, Anderson MK, Rast JP. Evolution of antigen binding receptors. Annu Rev Immunol. 1999;17:109-147.

31. Björkström NK, Kekäläinen E, Mjösberg J. Tissue-specific effector functions of innate lymphoid cells. Immunology. 2013;139(4):416-427.

32. Fuchs A, Colonna M. Innate lymphoid cells in homeostasis, infection, chronic inflammation and tumors of the gastrointestinal tract. Curr Opin Gastroenterol. 2013;29(6):581-587.

33. Bostick JW, Zhou L. Innate lymphoid cells in intestinal immunity and inflammation. Cell Mol Life Sci. 2016;73(2):237-252.

34. Blazar BR, Murphy WJ, Abedi M. Advances in graft-versus-host disease biology and therapy. Nat Rev Immunol. 2012;12(6):443-458.

35. Ferrara JL, Levine JE, Reddy P, Holler E. Graft-versus-host disease. Lancet. 2009;373(9674):1550-1561.

36. Bianchi ME. DAMPs, PAMPs and alarmins: all we need to know about danger. J Leukoc Biol. 2007;81(1):1-5.

37. Chan JK, et al. Alarmins: awaiting a clinical response. JClin Invest. 2012;122(8):2711-2719.

38. Seong SY, Matzinger P. Hydrophobicity: an ancient damage-associated molecular pattern that initiates innate immune responses. Nat Rev Immunol. 2004;4(6):469-478.

39. Cao X. Self-regulation and cross-regulation of pattern-recognition receptor signalling in health and disease. Nat Rev Immunol. 2016;16(1):35-50.

40. Akira S, Uematsu S, Takeuchi O. Pathogen recognition and innate immunity. Cell. 2006;124(4):783-801.

41. Beutler BA. TLRs and innate immunity. Blood. 2009;113(7):1399-1407.

42. Martin NT, Martin MU. Interleukin 33 is a guardian of barriers and a local alarmin. Nat Immunol. 2016;17(2):122-131.

43. Arnoult D, Soares F, Tattoli I, Girardin SE. Mitochondria in innate immunity. EMBO Rep. 2011;12(9):901-910.

44. Kono H, Rock KL. How dying cells alert the immune system to danger. Nat Rev Immunol. 2008;8(4):279-289.

45. Shi Y, Evans JE, Rock KL. Molecular identification of a danger signal that alerts the immune system to dying cells. Nature. 2003;425(6957):516-521.

46. Bianchi ME, Manfredi AA. High-mobility group box 1 (HMGB1) protein at the crossroads between innate and adaptive immunity. Immunol Rev. 2007;220:35-46.

47. Li Q, Park PW, Wilson CL, Parks WC. Matrilysin shedding of syndecan-1 regulates chemokine mobilization and transepithelial efflux of neutrophils in 
acute lung injury. Cell.2002;111(5):635-646.

48. van der Velden WJ, Netea MG, de Haan AF, Huls GA, Donnelly JP, Blijlevens NM. Role of the mycobiome in human acute graft-versushost disease. Biol Blood Marrow Transplant. 2013;19(2):329-332.

49. Khakh BS, North RA. P2X receptors as cellsurface ATP sensors in health and disease. Nature. 2006;442(7102):527-532.

50. Wilhelm K, et al. Graft-versus-host disease is enhanced by extracellular ATP activating P2X7R. Nat Med.2010;16(12):1434-1438.

51. Klämbt V, et al. A novel function for P2Y2 in myeloid recipient-derived cells during graft-versushost disease. JImmunol. 2015;195(12):5795-5804.

52. Zhong $\mathrm{X}$, et al. The impact of $\mathrm{P} 2 \mathrm{X} 7$ receptor antagonist, brilliant blue $\mathrm{G}$ on graft-versus-host disease in mice after allogeneic hematopoietic stem cell transplantation. Cell Immunol. 2016;310:71-77.

53. Resta R, Yamashita Y, Thompson LF. Ectoenzyme and signaling functions of lymphocyte CD73. Immunol Rev. 1998;161:95-109.

54. Tsukamoto H, et al. Deficiency of CD73/ ecto-5'-nucleotidase in mice enhances acute graft-versus-host disease. Blood. 2012;119(19):4554-4564.

55. Wang L, Fan J, Chen S, Zhang Y, Curiel TJ, Zhang B. Graft-versus-host disease is enhanced by selective $\mathrm{CD} 73$ blockade in mice. PLoS One. 2013;8(3):e58397.

56. Lappas CM, Liu PC, Linden J, Kang EM, Malech HL. Adenosine A2A receptor activation limits graft-versus-host disease after allogenic hematopoietic stem cell transplantation. J Leukoc Biol. 2010;87(2):345-354.

57. Jankovic D, et al. The Nlrp3 inflammasome regulates acute graft-versus-host disease. J Exp Med. 2013;210(10):1899-1910.

58. Chen S, et al. MicroRNA-155-deficient dendritic cells cause less severe GVHD through reduced migration and defective inflammasome activation. Blood. 2015;126(1):103-112.

59. Matta BM, Reichenbach DK, Blazar BR, Turnquist HR. Alarmins and their receptors as modulators and indicators of alloimmune responses. Am J Transplant. 2017;17(2):320-327.

60. Lotze MT, Tracey KJ. High-mobility group box 1 protein (HMGB1): nuclear weapon in the immune arsenal. Nat Rev Immunol. 2005;5(4):331-342.

61. Park JS, et al. Involvement of toll-like receptors 2 and 4 in cellular activation by high mobility group box 1 protein. J Biol Chem. 2004;279(9):7370-7377.

62. Wang $\mathrm{H}$, et al. HMG-1 as a late mediator of endotoxin lethality in mice. Science. 1999;285(5425):248-251.

63. Im KI, et al. The free radical scavenger NecroX-7 attenuates acute graft-versus-host disease via reciprocal regulation of Th1/regulatory T cells and inhibition of HMGB1 release. J Immunol. 2015;194(11):5223-5232.

64. Yujiri T, et al. Increased serum levels of highmobility group box 1 protein in patients who developed acute graft-versus-host disease after allogeneic hematopoietic stem cell transplantation. Eur J Haematol. 2010;85(4):366-367.
65. Chen GY, Tang J, Zheng P, Liu Y. CD24 and Siglec-10 selectively repress tissue damage-induced immune responses. Science. 2009;323(5922):1722-1725.

66. Chen GY, et al. Broad and direct interaction between TLR and Siglec families of pattern recognition receptors and its regulation by Neu1. Elife. 2014;3:e04066.

67. Chen GY, et al. Amelioration of sepsis by inhibiting sialidase-mediated disruption of the CD24-SiglecG interaction. Nat Biotechnol. 2011;29(5):428-435.

68. Pillai S, Netravali IA, Cariappa A, Mattoo H. Siglecs and immune regulation. Апnи Rev Immunol.2012;30:357-392.

69. Toubai T, Mathewson ND, Magenau J, Reddy P. Danger signals and graft-versus-host disease: current understanding and future perspectives. Front Immunol. 2016;7:539.

70. Toubai T, et al. Siglec-G-CD24 axis controls the severity of graft-versus-host disease in mice. Blood. 2014;123(22):3512-3523.

71. Baranovski BM, Freixo-Lima GS, Lewis EC, Rider P. T helper subsets, peripheral plasticity, and the acute phase protein, $\alpha 1$-antitrypsin. Biomed Res Int. 2015;2015:184574.

72. Marcondes AM, et al. Inhibition of IL-32 activation by $\alpha-1$ antitrypsin suppresses alloreactivity and increases survival in an allogeneic murine marrow transplantation model. Blood. 2011;118(18):5031-5039.

73. Tawara I, et al. $\alpha$-1-Antitrypsin monotherapy reduces graft-versus-host disease after experimental allogeneic bone marrow transplantation. Proc Natl Acad Sci U S A. 2012;109(2):564-569.

74. Broz P, Dixit VM. Inflammasomes: mechanism of assembly, regulation and signalling. Nat Rev Immunol. 2016;16(7):407-420.

75. Granell M, et al. Common variants in NLRP2 and NLRP3 genes are strong prognostic factors for the outcome of HLA-identical sibling allogeneic stem cell transplantation. Blood. 2008;112(10):4337-4342.

76. Toubai T, et al. NLRP6 in host target tissues exacerbates graft-versus-host disease. Blood. 2015;126(23):148.

77. Elinav E, et al. NLRP6 inflammasome regulates colonic microbial ecology and risk for colitis. Cell. 2011;145(5):745-757.

78. Shlomchik WD. Graft-versus-host disease. Nat Rev Immunol. 2007;7(5):340-352.

79. Shlomchik WD, et al. Prevention of graft versus host disease by inactivation of host antigenpresenting cells. Science. 1999;285(5426):412-415.

80. Duffner UA, et al. Host dendritic cells alone are sufficient to initiate acute graft-versus-host disease. J Immunol. 2004;172(12):7393-7398.

81. Zhang Y, Louboutin JP, Zhu J, Rivera AJ, Emerson SG. Preterminal host dendritic cells in irradiated mice prime $\mathrm{CD} 8^{+} \mathrm{T}$ cell-mediated acute graft-versus-host disease. JClin Invest. 2002;109(10):1335-1344.

82. Koyama M, et al. Plasmacytoid dendritic cells prime alloreactive $\mathrm{T}$ cells to mediate graftversus-host disease as antigen-presenting cells. Blood. 2009;113(9):2088-2095.

83. Koyama M, et al. Recipient nonhematopoietic antigen-presenting cells are sufficient to induce lethal acute graft-versus-host disease. Nat Med. 2011;18(1):135-142.

84. Li H, et al. Profound depletion of host conventional dendritic cells, plasmacytoid dendritic cells, and B cells does not prevent graft-versus-host disease induction. J Immunol. 2012;188(8):3804-3811.

85. Tawara I, et al. Host basophils are dispensable for induction of donor $\mathrm{T}$ helper 2 cell differentiation and severity of experimental graft-versushost disease. Biol Blood Marrow Transplant. 2011;17(12):1747-1753.

86. Toubai T, et al. Induction of acute GVHD by sex-mismatched $\mathrm{H}-\mathrm{Y}$ antigens in the absence of functional radiosensitive host hematopoietic-derived antigen-presenting cells. Blood. 2012;119(16):3844-3853.

87. Kaufmann SH, Dorhoi A. Molecular determinants in phagocyte-bacteria interactions. Immunity. 2016;44(3):476-491.

88. Schwab L, et al. Neutrophil granulocytes recruited upon translocation of intestinal bacteria enhance graft-versus-host disease via tissue damage. Nat Med. 2014;20(6):648-654.

89. Giroux M, et al. SMAD3 prevents graft-versushost disease by restraining Th1 differentiation and granulocyte-mediated tissue damage. Blood. 2011;117(5):1734-1744.

90. van Bekkum DW, Knaan S. Role of bacterial microflora in development of intestinal lesions from graft-versus-host reaction. J Natl Cancer Inst. 1977;58(3):787-790.

91. Storb R, et al. Graft-versus-host disease and survival in patients with aplastic anemia treated by marrow grafts from HLA-identical siblings. Beneficial effect of a protective environment. N Engl J Med. 1983;308(6):302-307.

92. Beelen DW, Elmaagacli A, Muller KD, Hirche $\mathrm{H}$, Schaefer UW. Influence of intestinal bacterial decontamination using metronidazole and ciprofloxacin or ciprofloxacin alone on the development of acute graft-versus-host disease after marrow transplantation in patients with hematologic malignancies: final results and long-term follow-up of an open-label prospective randomized trial. Blood. 1999;93(10):3267-3275.

93. Shono Y, et al. Increased GVHD-related mortality with broad-spectrum antibiotic use after allogeneic hematopoietic stem cell transplantation in human patients and mice. Sci Transl Med. 2016;8(339):339ra71.

94. Weber D, et al. Rifaximin preserves intestinal microbiota balance in patients undergoing allogeneic stem cell transplantation. Bone Marrow Transplant. 2016;51(8):1087-1092.

95. Jenq RR, et al. Regulation of intestinal inflammation by microbiota following allogeneic bone marrow transplantation. J Exp Med. 2012;209(5):903-911.

96. Eriguchi Y, et al. Graft-versus-host disease disrupts intestinal microbial ecology by inhibiting Paneth cell production of $\alpha$-defensins. Blood. 2012;120(1):223-231.

97. Taur Y, et al. The effects of intestinal tract bacterial diversity on mortality following allogeneic hematopoietic stem cell transplantation. Blood. 2014;124(7):1174-1182.

98. Jenq RR, et al. Intestinal Blautia is associ- 
ated with reduced death from graft-versushost disease. Biol Blood Marrow Transplant. 2015;21(8):1373-1383.

99. Peled JU, Hanash AM, Jenq RR. Role of the intestinal mucosa in acute gastrointestinal GVHD. Blood. 2016;128(20):2395-2402.

100.Honda K, Littman DR. The microbiota in adaptive immune homeostasis and disease. Nature. 2016;535(7610):75-84

101. Maloy KJ, Powrie F. Intestinal homeostasis and its breakdown in inflammatory bowel disease. Nature. 2011;474(7351):298-306.

102. Mathewson ND, et al. Gut microbiome-derived metabolites modulate intestinal epithelial cell damage mitigate graft-versus-host disease. $\mathrm{Nat}$ Immunol. 2016;17(5):505-513.

103. Atarashi $\mathrm{K}$, et al. Treg induction by a rationally selected mixture of Clostridia strains from the human microbiota. Nature. 2013;500(7461):232-236

104. Furusawa Y, et al. Commensal microbe-derived butyrate induces the differentiation of colonic regulatory T cells. Nature. 2013;504(7480):446-450.

105. Jasperson LK, Bucher C, Panoskaltsis-Mortari A, Mellor AL, Munn DH, Blazar BR. Inducing the tryptophan catabolic pathway, indoleamine 2,3-dioxygenase (IDO), for suppression of graftversus-host disease (GVHD) lethality. Blood. 2009;114(24):5062-5070.

106.Sun Y, et al. Cutting edge: Negative regulation of dendritic cells through acetylation of the nonhistone protein STAT-3. J Immunol. 2009;182(10):5899-5903.

107. Mellor AL, et al. Prevention of T cell-driven complement activation and inflammation by tryptophan catabolism during pregnancy. Nat Immunol. 2001;2(1):64-68.

108. Ravishankar B, et al. Tolerance to apoptotic cells is regulated by indoleamine 2,3-dioxygenase. Proc Natl Acad Sci U S A. 2012;109(10):3909-3914.

109. Weber D, et al. Low urinary indoxyl sulfate levels early after transplantation reflect a disrupted microbiome and are associated with poor outcome. Blood. 2015;126(14):1723-1728.

110. Akahoshi M, et al. A case of transfusionassociated graft-versus-host disease not prevented by white cell-reduction filters. Transfusion. 1992;32(2):169-172.

111. Tawara I, et al. Interleukin-6 modulates graftversus-host responses after experimental allogeneic bone marrow transplantation. Clin Cancer Res. 2011;17(1):77-88.

112. Reddy P. Pathophysiology of acute graft-versushost disease. Hematol Oncol. 2003;21(4):149-161.

113. Chen X, et al. Blockade of interleukin- 6 signaling augments regulatory T-cell reconstitution and attenuates the severity of graft-versus-host disease. Blood. 2009;114(4):891-900.

114. McDonald-Hyman C, Turka LA, Blazar BR. Advances and challenges in immunotherapy for solid organ and hematopoietic stem cell transplantation. Sci Transl Med. 2015;7(280):280rv2.

115. Teshima T, Maeda Y, Ozaki K. Regulatory T cells and IL-17-producing cells in graft-versus-host disease. Immunotherapy. 2011;3(7):833-852.

116. Hill GR, Ferrara JL. The primacy of the gastrointestinal tract as a target organ of acute graftversus-host disease: rationale for the use of cyto- kine shields in allogeneic bone marrow transplantation. Blood.2000;95(9):2754-2759.

117. Burman AC, et al. IF Ngamma differentially controls the development of idiopathic pneumonia syndrome and GVHD of the gastrointestinal tract. Blood. 2007;110(3):1064-1072.

118. Nikolic B, Lee S, Bronson RT, Grusby MJ, Sykes $\mathrm{M}$. Th1 and Th2 mediate acute graft-versus-host disease, each with distinct end-organ targets. JClin Invest. 2000;105(9):1289-1298.

119. Yu Y, Wang D, Semple D, Anasetti C, Yu X-Z. Separation fo graft-versus-hsot disease graftversus-leukemia effects by targeting T-bet ROR $\gamma \mathrm{T}$ transcription factors. American Society of Hematology. Orlando, Florida; 2010:Oral Poster \#1098.

120. Yu Y, et al. Prevention of GVHD while sparing GVL effect by targeting Th1 and Th17 transcription factor T-bet and ROR $\gamma$ t in mice. Blood. 2011;118(18):5011-5020.

121. Fulton LM, et al. Attenuation of acute graftversus-host disease in the absence of the transcription factor ROR $\gamma \mathrm{t}$. J Immunol. 2012;189(4):1765-1772.

122. Markey KA, MacDonald KP, Hill GR. The biology of graft-versus-host disease: experimental systems instructing clinical practice. Blood. 2014;124(3):354-362.

123. Gartlan $\mathrm{KH}$, et al. Tc17 cells are a proinflammatory, plastic lineage of pathogenic $\mathrm{CD} 8^{+} \mathrm{T}$ cells that induce GVHD without antileukemic effects. Blood.2015;126(13):1609-1620.

124. Varelias A, et al. Acute graft-versus-host disease is regulated by an IL-17-sensitive microbiome [published online ahead of print Jan, 2017]. Blood. https://doi.org/10.1182/blood2016-08-732628.

125. Das R, Chen X, Komorowski R, Hessner MJ, Drobyski WR. Interleukin-23 secretion by donor antigen-presenting cells is critical for organspecific pathology in graft-versus-host disease. Blood. 2009;113(10):2352-2362.

126.Zhou V, et al. A colitogenic memory CD4 $\mathrm{T}$ cell population mediates gastrointestinal graft-versus-host disease. J Clin Invest. 2016;126(9):3541-3555.

127. Vander Lugt MT, et al. ST2 as a marker for risk of therapy-resistant graft-versus-host disease and death. N Engl J Med. 2013;369(6):529-539.

128. Reichenbach DK, et al. The IL-33/ST2 axis augments effector T-cell responses during acute GVHD. Blood. 2015;125(20):3183-3192.

129.Zhang J, et al. ST2 blockade reduces sST2producing $\mathrm{T}$ cells while maintaining protective mST2-expressing T cells during graft-versus-host disease. Sci Transl Med. 2015;7(308):308ra160.

130. Matta BM, et al. Peri-alloHCT IL-33 administration expands recipient $\mathrm{T}$-regulatory cells that protect mice against acute GVHD. Blood. 2016;128(3):427-439.

131. Eriguchi Y, et al. Graft-versus-host disease disrupts intestinal microbial ecology by inhibiting Paneth cell production of $\alpha$-defensins. Blood 2012;120(1):223-231.

132. Vaishnava S, et al. The antibacterial lectin RegIII $\gamma$ promotes the spatial segregation of microbiota and host in the intestine. Science. 2011;334(6053):255-258
133. Hanash AM, et al. Interleukin-22 protects intestinal stem cells from immune-mediated tissue damage and regulates sensitivity to graft versus host disease. Immunity. 2012;37(2):339-350.

134. Sato T, et al. Paneth cells constitute the niche for Lgr5 stem cells in intestinal crypts. Nature. 2011;469(7330):415-418.

135. Lindemans CA, et al. Interleukin-22 promotes intestinal-stem-cell-mediated epithelial regeneration. Nature. 2015;528(7583):560-564.

136. Reya T, Clevers $\mathrm{H}$. Wnt signalling in stem cells and cancer. Nature. 2005;434(7035):843-850.

137. Takashima S, et al. The Wnt agonist R-spondin1 regulates systemic graft-versus-host disease by protecting intestinal stem cells. JExp Med. 2011;208(2):285-294.

138. Bruce DW, et al. Type 2 innate lymphoid cells treat and prevent acute gastrointestinal graftversus-host disease [published online ahead of print April 4, 2017]. J Clin Invest. https://doi. org/10.1172/JCI91816.

139. Munneke JM, et al. Activated innate lymphoid cells are associated with a reduced susceptibility to graft-versus-host disease. Blood. 2014;124(5):812-821.

140.Vely F, et al. Evidence of innate lymphoid cell redundancy in humans. Nat Immunol. 2016;17(11):1291-1299.

141. Hartwell MJ, et al. An early-biomarker algorithm predicts lethal graft-versus-host disease and survival. JCI Insight. 2017;2(3):e89798.

142.Ferrara JL, et al. Regenerating islet-derived $3-\alpha$ is a biomarker of gastrointestinal graft-versus-host disease. Blood. 2011;118(25):6702-6708.

143. Levine JE, et al. Low Paneth cell numbers at onset of gastrointestinal graft-versus-host disease identify patients at high risk for nonrelapse mortality. Blood. 2013;122(8):1505-1509.

144. Marcondes AM, et al. Response of steroidrefractory acute GVHD to $\alpha 1$-antitrypsin. Biol Blood Marrow Transplant. 2016;22(9):1596-1601.

145. Kennedy GA, et al. Addition of interleukin-6 inhibition with tocilizumab to standard graftversus-host disease prophylaxis after allogeneic stem-cell transplantation: a phase $1 / 2$ trial. Lancet Oncol. 2014;15(13):1451-1459.

146.Waldman $\mathrm{E}$, et al. Absence of $\beta 7$ integrin results in less graft-versus-host disease because of decreased homing of alloreactive $\mathrm{T}$ cells to intestine. Blood. 2006;107(4):1703-1711.

147. Aoyama K, et al. Inhibiting retinoic acid signaling ameliorates graft-versus-host disease by modifying T-cell differentiation and intestinal migration. Blood. 2013;122(12):2125-2134.

148. Petrovic A, et al. LPAM ( $\alpha 4 \beta 7$ integrin) is an important homing integrin on alloreactive $\mathrm{T}$ cells in the development of intestinal graft-versushost disease. Blood. 2004;103(4):1542-1547.

149. Ueha S, et al. Intervention of MAdCAM-1 or fractalkine alleviates graft-versus-host reaction associated intestinal injury while preserving graft-versus-tumor effects. J Leukoc Biol. 2007;81(1):176-185

150. Das R, et al. Blockade of interleukin-23 signaling results in targeted protection of the colon and allows for separation of graft-versus-host and graft-versus-leukemia responses. Blood. 2010;115(25):5249-5258. 
151. Pidala J, Perez L, Beato F, Anasetti C. Ustekinumab demonstrates activity in glucocorticoid-refractory acute GVHD. Bone Marrow Transplant. 2012;47(5):747-748.

152. Min CK, et al. Paradoxical effects of interleukin-18 on the severity of acute graftversus-host disease mediated by $\mathrm{CD} 4^{+}$and CD8 ${ }^{+} \mathrm{T}$-cell subsets after experimental allogeneic bone marrow transplantation. Blood. 2004;104(10):3393-3399.

153. Park MJ, et al. IL-1 receptor blockade alleviates graft-versus-host disease through downregulation of an interleukin-1 $\beta$-dependent glycolytic pathway in Th17 cells. Mediators Inflamm. 2015;2015:631384.

154.Antin JH, et al. Interleukin-1 blockade does not prevent acute graft-versus-host disease: results of a randomized, double-blind, placebo-controlled trial of interleukin-1 receptor antagonist in allogeneic bone marrow transplantation. Blood. 2002;100(10):3479-3482.

155. McCarthy PL Jr, et al. Inhibition of interleukin-1 by an interleukin-1 receptor antagonist prevents graft-versus-host disease. Blood. 1991;78(8):1915-1918.

156. Eriguchi Y, et al. Graft-versus-host disease disrupts intestinal microbial ecology by inhibiting Paneth cell production of $\alpha$-defensins. Blood.
2012;120(1):223-231.

157. Weber D, et al. Microbiota disruption induced by early use of broad-spectrum antibiotics is an independent risk factor of outcome after allogeneic stem cell transplantation [published online ahead of print February 14, 2017]. Biol Blood Marrow Transplant. https://doi.org/10.1016/j. bbmt.2017.02.006.

158. Gerbitz A, et al. Probiotic effects on experimental graft-versus-host disease: let them eat yogurt. Blood. 2004;103(11):4365-4367.

159. Gilbert KM, Boger S, Fifer EK. Butyric acid derivative induces allospecific $\mathrm{T}$ cell anergy and prevents graft-versus-host disease. Immunopharmacol Immunotoxicol. 2003;25(1):13-27.

160.Dudakov JA, et al. Interleukin-22 drives endogenous thymic regeneration in mice. Science. 2012;336(6077):91-95.

161. Koehn BH, et al. GVHD-associated, inflammasome-mediated loss of function in adoptively transferred myeloid-derived suppressor cells. Blood. 2015;126(13):1621-1628.

162. Highfill SL, et al. Bone marrow myeloid-derived suppressor cells (MDSCs) inhibit graft-versushost disease (GVHD) via an arginase-1dependent mechanism that is up-regulated by interleukin-13. Blood. 2010;116(25):5738-5747.

163.Zhou Z, et al. Development and function of myeloid-derived suppressor cells generated from mouse embryonic and hematopoietic stem cells. Stem Cells. 2010;28(3):620-632.

164. Taylor PA, Lees CJ, Blazar BR. The infusion of ex vivo activated and expanded CD4(+) CD25(+) immune regulatory cells inhibits graft-versus-host disease lethality. Blood. 2002;99(10):3493-3499.

165. Edinger $\mathrm{M}$, et al. $\mathrm{CD} 4{ }^{+} \mathrm{CD} 25^{+}$regulatory $\mathrm{T}$ cells preserve graft-versus-tumor activity while inhibiting graft-versus-host disease after bone marrow transplantation. Nat Med.2003;9(9):1144-1150.

166. Sandhu KS, et al. Umbilical cord blood transplantation outcomes in acute myelogenous leukemia/myelodysplastic syndrome patients aged $\geq 70$ years. Biol Blood Marrow Transplant. 2016;22(2):390-393.

167. Martelli MF, et al. HLA-haploidentical transplantation with regulatory and conventional T-cell adoptive immunotherapy prevents acute leukemia relapse. Blood. 2014;124(4):638-644.

168. Aggarwal S, Pittenger MF. Human mesenchymal stem cells modulate allogeneic immune cell responses. Blood. 2005;105(4):1815-1822.

169. Beyth S, et al. Human mesenchymal stem cells alter antigen-presenting cell maturation and induce T-cell unresponsiveness. Blood. 2005;105(5):2214-2219. 